\title{
De George W. Bush a Donald J. Trump: a África na política externa dos Estados Unidos, 2001-2020
}

\author{
From George W. Bush to Donald J. Trump: Africa in the US foreign policy, 2001-2020
}

DOI: $\underline{\text { https://doi.org/10.22456/2178-8839.112123 }}$

Anselmo Otavio

Universidade do Vale do Rio dos Sinos, São Leopoldo, Brasil

\section{Resumo}

Nos anos finais da administração Clinton (1994-2001) e, destacadamente, durante a Guerra contra o Terror (GcT), a interação entre os Estados Unidos (EUA) e a África se intensificou. Por simbolizar certo contraponto ao histórico distanciamento, ao menos nas relações internacionais, entre as partes, esta proximidade nos leva ao seguinte questionamento: a presença dos EUA representou, ou não, rompimento com a condição marginal do continente africano nos interesses de Washington? Pautando-se nesta questão, o artigo se propõe a compreender o lugar da África na política externa dos Estados Unidos entre 2001 e 2020, e defender a hipótese de que não houve tal rompimento. Primeiramente porque durante as administrações Bush (2001-2009) e Obama (2009-2017), o predomínio de iniciativas direcionadas a segurança indicou a continuidade do enquadramento da África nos interesses dos EUA no âmbito sistêmico, e não necessariamente a mudança de status deste continente na política externa norte-americana. Em segundo, porque o desinteresse pela África foi predominante ao longo do governo Trump (2017-2021). Em termos metodológicos, o artigo será desenvolvido a partir de revisão bibliográfica de caráter variado, composto por livros, artigos, revistas acadêmicas, documentos oficiais, relatórios, dentre outras fontes consideradas relevantes ao tema.

Palavras-chave: África; Estados Unidos; Política Externa;

\begin{abstract}
In the final years of the Clinton administration (1994-2001) and, most notably, during the War on Terror (GcT), United States of America (USA) and Africa relations were intensified. As it symbolizes a certain counterpoint to the historical distance, at least in international relations, between USA and African countries, this proximity leads us to the following question: did the presence of the United States represent, or not, a break with the marginal condition of the African continent in Washington's interests? Based on this issue, the article proposes to understand the Africa in the foreign policy of the United States between 2001 and 2020, and to defend the hypothesis that there was no such break. Firstly, during the Bush (2001-2009) and Obama (2009-2017) administrations, the predominance of security-oriented initiatives indicated the continuity of the USA in including Africa to its systemic interests, and does not necessarily reflect the changing status of this continent in U.S. foreign policy. Second, because disinterest in Africa was prevalent throughout the Trump administration (2017-2021). In methodological terms, the article will be developed from a bibliographic review, composed of books, articles, academic journals, official documents, reports, among other sources considered relevant to the theme.
\end{abstract}

Keywords: Africa; Foreign Policy; The United States of America; 


\section{Introdução}

Em 1992, o The New York Times publicou o Defense Planning Guidance (DPG), documento vazado que havia sido elaborado por membros dos Departamentos de Estado e de Defesa. Embora não implementado, o DPG indicava que Washington deveria se beneficiar do término da disputa Leste-Oeste para garantir a manutenção do sistema internacional favorável a seus interesses, utilizando da supremacia militar e de iniciativas de caráter unilateral como meios de eliminar qualquer possibilidade de ascensão de outra grande potência que, consequentemente, rivalizaria com a unipolaridade norte-americana. Inclusive, o DPG destacava a necessidade de Washington atuar de forma diferenciada para cada continente ou região, como na Europa Oriental, com o englobamento dos antigos países-membros da União Soviética na Organização do Tratado do Atlântico Norte (OTAN), e no Oriente Médio, via estabilização da região e acesso ao petróleo (THE NEW YORK TIMES, 1992; PECEQUILO, 2017).

Por um lado, a existência do DPG ilustrava que os Estados Unidos buscariam atuar no sistema internacional com o intuito de exercer ou dar continuidade à sua preponderância. Por outro lado, quando analisado ao longo dos anos 1990 , é possível indicar que neste novo cenário o continente africano mantinha-se marginal nos planos de Washington. Tal constatação pôde ser encontrada em grande parte da administração Clinton (1993-2001), com a retirada dos EUA da missão de Paz das Nações Unidas para a Somália após a morte de soldados norte-americanos em Mogadício (1993), o distanciamento de países como Zaire (atual República Democrática do Congo), Sudão e Quênia, e, destacadamente, no contraste entre o ativismo em questões humanitárias no Leste Europeu em detrimento a inação na África. De fato, se na Bósnia (1992-1995) e no Kosovo (1998-1999) o que se viu foi o intenso apoio via OTAN, em Ruanda, o ativismo contra tragédias humanitárias não foi encontrado na guerra entre Hutus e Tutsis, conflito que levou à morte de 11\% da população ruandesa (THOMSON, 2018). ${ }^{1}$

Nos anos finais da administração democrata, contudo, a sinalização de um potencial interesse foi encontrada em iniciativas como o repasse de US\$ 200 milhões em assistência para a Libéria, e na aprovação da African Growth and Opportunity Act (AGOA), lei voltada à maior interação entre Washington e países da África Subsaariana (BANJO, 2010). Por simbolizar certo contraponto ao histórico distanciamento, ao menos nas relações internacionais, entre as partes, tal proximidade nos leva ao seguinte questionamento: a presença dos EUA representou, ou não, rompimento com a condição marginal do continente africano nos interesses de Washington? Pautando-se nesta questão, o artigo se propõe a compreender o lugar da África na política externa dos Estados Unidos entre 2001 e 2020, e defender a hipótese de que não houve tal rompimento.

Por um lado, não houve o rompimento com a condição marginal, visto que durante as administrações Bush (20012009) e Obama (2009-2017) o predomínio de iniciativas direcionadas à segurança indicou a continuidade do enquadramento da África nos interesses dos EUA no âmbito sistêmico, e não necessariamente a mudança de status deste continente na política externa norte-americana. Por outro lado, porque o desinteresse pela África foi predominante ao longo do governo Trump (2017-2021). Em termos metodológicos, o artigo será desenvolvido a partir de revisão bibliográfica de caráter variado, composta por livros, artigos, revistas acadêmicas, bem como por documentos oficiais, relatórios, dentre outros materiais considerados relevantes ao tema.

\section{A administração Bush (2001-2009) e o englobamento da África na Guerra contra o Terror}

Em artigo intitulado de Benevolent Empire, publicado em 1998, Kagan destacava a importância e os benefícios da hegemonia dos Estados Unidos para o mundo. Para o autor, além de refletida na superioridade econômica e pela

\footnotetext{
${ }^{1}$ A Guerra da Bósnia foi o resultado dos conflitos entre mulçumanos, croatas e sérvios, sendo os dois primeiros favoráveis à independência com relação a Iugoslávia, e o último a unificação da Bósnia com a Sérvia. Já a Guerra no Kosovo foi resultado da não aceitação dos nacionalistas sérvios com relação a independência kosovar, defendida pela população albano-kosovar (JUDT, 2005).
} 
preponderância militar, cujo poder encontra equivalência apenas no Império Romano, a hegemonia norte-americana também era reflexo da identificação e internalização, por parte de Washington, dos interesses e anseios de outros países, fator que levava os EUA a atrelar seu bem-estar, sua liberdade, sua prosperidade e sua segurança, ao próprio sistema internacional. Nesse sentido, e parafraseando Samuel Huntington, destacava a importância do domínio norte-americano como instrumento de preservação da segurança e prosperidade mundial, visto que "um mundo sem a primazia e influência dos Estados Unidos seria um lugar mais violento, sem ordem, menos democrático e com baixo crescimento econômico” (KAGAN, 198, s.p, tradução nossa).

Curiosamente, dez anos após a publicação de Kagan (1998), em artigo intitulado de The future of american power: how America can survive the rise of the rest, Zakaria (2008) demonstrava a necessidade de os Estados Unidos reverem sua estratégia, uma vez que a conjuntura internacional já não mais era favorável a Washington. Embora afirmando a preponderância militar e econômica dos EUA, Zakaria (2008) destacava que os Estados Unidos não estavam mais isentos da perda do posto de liderança do sistema internacional, uma vez que não estavam sozinhos no mundo e seria necessário reconhecer que outras potências estavam em ascensão.

As diferenças encontradas em Kagan (1998) e em Zakaria (2008) refletem um dos principais debates que ganhou força a partir da década de 1990, qual seja, o declínio do poder norte-americano. Discutindo sobre o término das duas hegemonias anteriores, no caso, Holanda e Inglaterra, Arrighi (1996) destaca que tais debacles encontravam-se relacionadas à intensificação da rivalidade, ao surgimento de novos loci (locais) de poder distantes da atuação da hegemonia, e a expansão financeira por todo o sistema que se mantinha centralizada no país hegemônico. Referente aos EUA, Arrighi (1996) considera que desde as últimas décadas da disputa Leste-Oeste havia sinais que demonstravam o declínio desta hegemonia, constatado pelo aumento da rivalidade entre Washington e Moscou a partir dos anos finais da década de 1970; pelo renascimento da Ásia como loci de poder no sistema; e pela expansão financeira resultante do retorno a corrida armamentista engendrada principalmente durante a administração Reagan (1981-1989). ${ }^{2}$

Embora havendo essa tendência ao declínio do poder norte-americano, é fato que no pós-Guerra Fria as administrações norte-americanas não apenas buscaram exercer a hegemonia, mas, fundamentalmente, criar meios voltados à manutenção de sua existência. Exemplo disso pôde ser encontrado durante a administração George W. Bush, cuja vitória sobre o candidato do Partido Democrata, Al Gore, simbolizou o retorno do Partido Republicano à presidência e mudanças na política externa dos EUA. Neste caso, a tendência inicial era a adoção do isolacionismo, encontrado na rejeição de iniciativas como o Tratado de Kyoto, o Tribunal Penal Internacional, a Convenção de Armas Biológicas, dentre outros, considerados como limitantes à atuação de Washington. Entretanto, com os ataques de 11 setembro de 2001, o que se viu foi um novo processo de inserção internacional (PECEQUILO, 2011), refletido na invasão ao Afeganistão, objetivando combater o Talibã e a Al Qaeda, e consolidado com a criação da Estratégia de Defesa Nacional (NSS, na sigla em inglês) de 2002, documento que expunha o interesse da administração Bush em combater o terrorismo internacional.

Comumente conhecido como Doutrina Bush, o combate ao terrorismo internacional traz em sua gênese a influência dos neoconservadores, grupo defensor de pontos como a democracia, liberdade, combate ao comunismo e, destacadamente, a negativa acerca do relativismo cultural, uma vez que consideram os valores norte-americanos fundamentais para a prosperidade dos países (TEIXEIRA, 2007; FROELICH, 2005). Grosso modo, diante desta percepção hegemônica na qual Washington seria fundamental para atuar em um mundo marcado pela insegurança, os ataques de 11/09 representavam uma ameaça à paz mundial, e lançavam dois caminhos diametralmente opostos aos países, quais sejam, ou de estarem entre os civilizados, ou aderirem a bárbarie (HIRSH, 2002; NSS, 2002). ${ }^{3}$

Junto a esta especificidade, a Doutrina também possuía outras três características. A primeira, e de certo modo a própria essência desta doutrina, era a Guerra contra o Terror (GcT), isto é, conflito contra um inimigo não -convencional e

\footnotetext{
${ }^{2}$ Por hegemonia entende-se como a capacidade que um determinado Estado possui para exercer a liderança e o governo de um sistema composto por nações soberanas (ARRIGHI, 1996).

${ }^{3}$ Nas palavras de Bush, ou "[we] build a world of justice, or we will live in a world of coercion” (BUSH, 2002 apud NSS, 2002 ).
} 
assimétrico, marcado pela imprevisibilidade de um ataque e pela inexatidão, tanto do número de grupos terroristas quanto se estes possuíam, ou não, armas de destruição em massa. Já a segunda encontra-se atrelada à estratégia para a efetivação da GcT, no caso, o fortalecimento de parcerias antigas, principalmente com países pertencentes a OTAN, como também novas alianças, refletidas na maior interação entre EUA e o Paquistão (ALMEIDA, 2002; NSS, 2002; WIJK, 2002). Por fim, a terceira característica da Doutrina era garantir a legitimidade aos EUA em atuar de modo unilateral no sistema internacional.

Desejado desde a criação do DPG, o unilateralismo era compreendido como importante no enquadramento de determinados países em dois grupos de Estados que, de modo geral, remetiam ao governo anterior. O primeiro grupo refere-se aos chamados Estados Bandidos (Rogue States), que englobava Estados organizados politicamente, mas que possuíam administrações consideradas autoritárias e desafiadoras da liderança de Washington. Já o segundo diz respeito aos Estados Falidos (Failed States), caracterizados pela incapacidade em garantir condições básicas de existência, e por serem locais onde grupos fundamentalistas atuam (DERGHOUKASSIAN, 2002). Se na administração Clinton (1994 -2001) tais Estados eram considerados antidemocráticos, violadores dos direitos humanos, e apresentavam riscos à segurança mundial e, especificamente, aos norte-americanos, no governo Bush, Rogue e Failed States, passavam a fazer parte do chamado Eixo do Mal.

Discutindo sobre a GcT, Ikenberry (2002) a representava como um importante instrumento para a manutenção do poder norte-americano, uma vez que garantiria a criação e consolidação de uma terceira grande estratégia, que substituiria as duas anteriores criadas ao longo da década de 1940. Segundo o autor, a primeira grande estratégia, de orientação realista, trazia como objetivo conter o avanço comunista simbolizado pela União Soviética, utilizando de meios como o poder militar, a presença na Europa e no Leste Asiático, a construção de parceiras estratégicas, dentre outros caminhos considerados relevantes para tal finalidade. Junto a esta primeira, a segunda grande estratégia, de cunho liberal, encontra-se na esfera econômica, direcionada à abertura das economias. Neste caso, a liberalização econômica somava-se à valorização dos regimes democráticos e ao multilateralismo refletido na criação e valorização das organizações internacionais.

Por um lado, tais estratégias foram fundamentais para a liderança de Washington, uma vez que levaram países considerados estratégicos, como Japão e potências da Europa Ocidental, a obterem acesso ao mercado consumidor norteamericano e investimentos em tecnologia e segurança; e, em contrapartida, o aceite destes dos interesses e do poder norteamericanos, bem como em atuarem de forma favorável à contenção da União Soviética. Por outro lado, as mesmas estratégias foram as bases da ordem internacional predominante no pós-2a Guerra Mundial, também conhecida como Ordem Internacional Liberal (OIL) que, desde então, se mantinha pautada na defesa da democracia, da segurança internacional, das instituições internacionais, do livre comércio, dentre outras características vistas como relevantes pelos EUA. Entretanto, com o advento da administração Bush e, destacadamente após os ataques de 11/09, o que se viu foi a busca em adequar a ordem internacional via criação e consolidação de uma terceira grande estratégia, fiel à manutenção dos Estados Unidos como única grande potência, porém, baseada no poder bélico-militar (IKENBERRY, 2002).

Evidentemente que o destaque dado ao poder bélico-militar já era encontrado no DPG e durante a administração Clinton, como em 1998, quando o democrata aumentou os recursos orçados para as forças armadas (WIJK, 2002), no entanto, com o advento da GcT, tal poder passou a ser visto como fundamental para a execução dos sete elementos símbolos desta terceira grande estratégia. Segundo Ikenberry (2002), tais elementos seriam a manutenção da unipolaridade; a ressignificação de ameaça global - visto que o terrorismo é uma ameaça não-estatal -; a reconceituação da dissuasão; a ressignificação da soberania, uma vez que tanto a dissuasão quanto a soberania são desrespeitadas pelos; a depreciação e desvalorização de parcerias tradicionais, das regras, tratados e normas internacionais; na irrestrita atuação de Washington no combate a este inimigo; e desvalorização da estabilidade internacional, refletida na negação ou abandono de acordos voltados ao controle de armas. Em certa medida, a busca em garantir a si o direito de realizar 
intervenções de caráter unilateral, desconsiderando o direito internacional e as organizações internacionais, pôde ser encontrada na Guerra contra o Iraque, em 2003, quando a invasão norte-americana foi respaldada apenas de um grupo pequeno de países, dos quais se destacaram a Inglaterra e o Japão, e questionada por grande parte da comunidade internacional (PECEQUILO, 2017).

Diante deste cenário de maior atuação norte-americana na adequação da ordem internacional, o que se viu foi a ampliação das iniciativas direcionadas ao continente africano em áreas da economia, saúde e, destacadamente, segurança. No âmbito econômico, vale destacar a manutenção da AGOA, que em 2004, obteve sua vigência expandida até 2015. Junto a AGOA, vale destacar a criação do Millennium Challenge Corporation (MCC) em 2004, iniciativa direcionada ao desenvolvimento econômico que, mesmo não sendo voltada exclusivamente para a África, auxiliou diversos países africanos (KATITO, 2010). Na saúde, Washington ampliou a cooperação no âmbito sanitário, com o investimento de US\$ 200 milhões para o Fundo Global de combate à tuberculose, malária e ao HIV/AIDS e US\$ 500 milhões direcionada ao combate do HIV/AIDS especificamente para mães e crianças. Além disso, entre 2005 e 2008, em torno de US\$ 25 bilhões foram direcionados ao Plano de Emergência Presidencial de Combate à AIDS (PEPFAR, na sigla em inglês). Semelhantemente ao MCC, o Fundo Global e o PEPFAR também não eram exclusivos para a África, porém, assistiram diversos países africanos (TIEKU, 2018).

No âmbito da segurança, as iniciativas estiveram relacionadas à GcT, e não necessariamente às demandas securitárias dos países africanos. Exemplos disso podem ser encontrados nos programas Foreign Military Sales (FMS) e Foreign Military Sales Financing (FMF), ambos voltados a facilitar a venda de armas e equipamentos militares para países aliados de Washington via provisão de créditos. Neste caso, se entre 2004 e 2005 o valor direcionado para o continente foi de US\$25,6 milhões para US\$ 61,5 milhões, quando analisado por países, só em 2005, Quênia (US\$ 23,5 milhões) e Djibuti (US\$19,5 milhões) ficaram com aproximadamente 70\% do valor repassado ao continente, com o restante sendo dividido por países como Botsuana, Eritreia, Etiópia, Nigéria e Uganda (KLARE; VOLMAN, 2006). A importância de Nairobi para a administração Bush pode ser encontrada em outros repasses, como US\$ 10 milhões advindos do East Africa Counter Terrorism Initiative (EACTI, na sigla em inglês) e US\$12,28 milhões do United States Antiterrorism Assistance Program (ATA, na sigla em inglês), ambos voltados à contenção do terrorismo (TIEKU, 2018).

Paralelamente às iniciativas anteriormente apresentadas, outras duas que se destacaram foram a Iniciativa norteamericana de Combate ao Terrorismo na África Ocidental - que direcionou US\$ 100 milhões em recursos e assistência técnica -, e o Programa Safe Skies para África - voltado à segurança nos aeroportos -, ambas direcionadas a países como Djibuti, Eritreia, Etiópia, Quênia, Tanzânia e Uganda. Além destes, outra que ganhou importância foi a Iniciativa Pan-Sahel (PSI, na sigla em inglês), voltada à defesa de fronteiras em países como Chade, Argélia, Marrocos, Nigéria, Senegal, Tunísia, Mali, Mauritânia e Níger, que entre os anos 2002 e 2003, recebeu em torno de US\$ 16 milhões (KLARE; VOLMAN, 2006). Junto ao PSI, vale destacar a Força-Tarefa Conjunta Combinada da África (CJTF-HOA, na sigla em inglês) que, entre 2002 e 2009 capacitou quadros militares em países como Etiópia, Djibuti, Quênia, Burundi, Tanzânia e Ruanda. Em linhas gerais, se entre 1997 e 2001 os repasses relacionados à segurança e à defesa haviam aumentado em torno de US\$ 40 milhões, em 2006 o montante chegava a US\$ 130 milhões (TIEKU, 2018).

Grosso modo, o que foi visto no CJTF-HOA também se refletiu em outra iniciativa importante para a aproximação dos EUA junto aos países africanos, qual seja, o International Military Education and Training (IMET, na sigla em inglês). Voltado à capacitação técnica de quadros africanos, o IMET alocou em torno de US\$ 10 milhões por ano, treinando entre 1.300 e 1.700 africanos. Referente aos países, em 2006, por exemplo, os que mais receberam recursos desta iniciativa foram Nigéria (US\$ 800.000), Argélia (US\$ 750.000), Etiópia (US\$ 600.000), Eritréia (US\$ 450.000) e Angola (US\$ 400.000) (KLARE; VOLMAN, 2006). No entanto, ainda que importantes, vale destacar que a principal iniciativa desenvolvida pela administração Bush no âmbito da GcT diz respeito ao estabelecimento do Comando dos Estados Unidos para a África (AFRICOM, na sigla em inglês). 
Direcionado a atuar em operações, exercícios, capacitação de soldados, cooperação com países africanos, dentre outros objetivos pertencentes à esfera da segurança, o AFRICOM pode ser caracterizado tanto pela sua atuação, como também pelas críticas realizadas a sua funcionalidade. Atuação, visto que auxilia a União Africana (UA) em iniciativas direcionadas à estabilidade do continente, como na Missão de Paz da União Africana para a Somália (AMISOM), cuja atuação norte-americana esteve atrelada ao suporte a contingentes ugandenses em território somali e no fornecimento de equipamentos militares para esta missão (BANJO, 2010; CARDOSO, 2020).

Críticas, uma vez que além de não contar com a participação dos países africanos em sua criação, o AFRICOM passou a simbolizar a seletividade de Washington em atuar apenas em determinados conflitos, e não em garantir a estabilidade do continente como um todo. Reflexo disso pode ser encontrado na repulsa da quase totalidade das nações africanas em sedearem tal iniciativa, que foi locada em Stuttgart, Alemanha (BANJO, 2010; CARDOSO, 2020). Em certa medida, tais críticas, somadas ao predomínio de investimentos norte-americanos na dimensão da segurança se comparada com a saúde e a economia, refletiam uma das características já vistas em administrações anteriores, qual seja, de atuar no continente quando este passa a ser englobado em interesses sistêmicos de Washington. Dito de outra forma, o objetivo não era necessariamente atender as demandas africanas, mas, fundamentalmente, romper com o terrorismo, visto como principal inimigo a estabilidade do sistema internacional.

No ano de 2009, a administração Bush chegava ao fim marcada por críticas à GcT e, consequentemente, pelo insucesso na criação e consolidação de uma terceira grande estratégia. Uma destas críticas atrela -se ao próprio adversário escolhido pelos EUA, inimigo que não é uma entidade, mas sim uma estratégia, bem como não se concentra em um único local. Inclusive, ao negar que a gênese do terrorismo se encontrava atrelada as constantes interferências das potências ocidentais no mundo islâmico, a submissão imposta por estas a grande parte das populações muçulmanas, principalmente na Palestina, a GcT, paradoxalmente, acabou por ampliar os ataques de cunho terrorista, visto que as intervenções no Afeganistão e no Iraque, bem como as sanções a países como o Irã, acabaram por elevar o antiamericanismo (JAGUARIBE, 2005).

Paralelamente a este paradoxo, outras críticas à GcT referem-se à não adesão, por grande parte de seus parceiros tradicionais, principalmente as potências europeias, e a incoerência encontrada nos atos de combate ao terrorismo. A não adesão relaciona-se à recusa em aceitarem a invasão norte-americana no Iraque, uma vez que a administração Bush perdeu credibilidade ao não conseguir estabelecer a relação entre o governo Saddam Hussein e a Al Qaeda, tampouco em provar que o regime iraquiano possuía armas de destruição em massa. Já a incoerência diz respeito à retórica da defesa dos direitos humanos e da democracia, seguida por atos que não condizem com a defesa de tais pontos, como os casos de tortura na Base Americana de Guantánamo (Cuba), e na prisão de Abu Graib (Iraque).

A incoerência destacada anteriormente também pôde ser encontrada no âmbito econômico, com o advento da crise financeira de 2007, cuja gênese esteve atrelada, primeiramente, ao reajuste nos juros das taxas hipotecárias, afetando diretamente os subprimes, e, posteriormente, a expansão desta crise no sistema bancário norte-americano como um todo. ${ }^{4}$ Inicialmente, o que se viu foi a não intervenção norte-americana, porém, com o advento da concordata do Lehman Brothers que, até aquele momento, era o quarto maior banco dos EUA, a administração Bush passou a atuar na economia, rompendo com uma das principais características do neoliberalismo, no caso, a não intervenção estatal na economia. Exemplos disso podem ser encontrados em 2008, com o Federal Reserve anunciando empréstimo de US\$14 bilhões para a General Motors e a Chrysler, e de US\$ 85 milhões ao American International Group Inc., assumindo 89\% das ações desta empresa (BRESSER-PEREIRA, 2009; CARVALHO, 2008).

\footnotetext{
4 "O termo subprime [...] identifica precisamente os indivíduos que não teriam renda, ou garantias, ou história de crédito que justificassem a concessão do empréstimo.” (CARVALHO, 2008, p.2).
} 


\section{A administração Obama (2009-2017) e os limites do engajamento norte-americano na África}

Ao tomar posse como presidente, Barack Obama indicou a necessidade dos norte-americanos romperem com a discórdia e privilegiarem a tolerância e, destacadamente, a união, compreendida como fundamental diante de uma sociedade cada vez mais fragmentada (OBAMA, 2009). É fato que a polarização já era vista durante as eleições, quando o candidato democrata disputou com a chapa Republicana encabeçada por John McCain (presidente) e Sarah Palin (vice), representante do Tea Party, movimento ultraconservador baseado na defesa do unilateralismo, da religião, e na contrariedade a pontos como o direito ao aborto e a expansão de direitos civis. Contudo, tal fragmentação mantinha -se presente, com as correntes mais radicais do neoconservadorismo ampliando sua influência (PECEQUILO, 2017).

Paralelamente a defesa da união na sociedade norte-americana, Obama considerava ser necessário rever a política externa dos EUA. Neste caso, o democrata entrava em consonância com o Renewing American Leadership, artigo de sua autoria que criticava a inserção internacional defendida por Bush. Publicado em 2007, na Foreign Policy, o artigo indicava que a renovação da liderança norte-americana passaria pelas dimensões militar, diplomática e moral. Referente à primeira, Obama considerava que os Estados Unidos deveriam reaparelhar suas forças armadas, encerrar a guerra no Iraque, combater grupos terroristas e a difusão de armas de destruição em massa, destacadamente as armas nucleares. Para tais realizações, a dimensão diplomática ganhava destaque, representada pela valorização do multilateralismo (valorização da ONU e da OTAN) e pela criação de parcerias com potências como China, Japão, Coréia do Sul, Brasil, Índia, Nigéria, África do Sul, dentre outras consideradas importantes para esta renovação da liderança americana (OBAMA, 2007).

Por fim, na esfera moral, compreendida como fundamental para romper com as incoerências deixadas pela administração Bush, os Estados Unidos deveriam voltar a defender pontos marcantes em sua história, como liberdade, democracia e direitos humanos, e se distanciar de práticas como a violência contra prisioneiros, a tortura, a retenção sem acusação ou julgamento, a locação em prisões secretas espalhadas em diversos países, dentre outras símbolos da GcT. Ainda nesta dimensão, e somada ao âmbito militar, Washington deveria auxiliar países pobres em processos de democratização e de luta contra a pobreza, ambos considerados fundamentais para mitigar com o terrorismo e conflitos internos, bem como com epidemias, destacadamente HIV/AIDS, malária e gripe aviária (OBAMA, 2007).

Por um lado, os pontos defendidos em 2007 não apenas representavam contraponto ao interesse da administração anterior em criar uma terceira grande estratégia pautada no poder militar, mas fundamentalmente sinalizava o respeito e a continuidade da OIL. Por outro lado, tais pontos também ganharam destaque com a Estratégia de Segurança Nacional dos Estados Unidos da América (NSS de 2010). Considerando a maior interconectividade entre os países, à NSS de 2010 indicava que, no âmbito da segurança, a administração Obama iria valorizar o conceito ampliado de segurança, bem como buscaria fortalecer o Tratado de Não Proliferação de Armas Nucleares (TNP), atuar na desnuclearização do Irã e da Coréia do Norte, dentre outros pontos considerados relevantes para a estabilidade do sistema internacional. Embora considerada como símbolo de encerramento da GcT, a NSS de 2010 não menosprezava o combate ao terrorismo, considerando fundamental a atuação norte-americana no desmantelamento da Al Qaeda. Inclusive, o reflexo desta continuidade pode ser encontrado nas expressões war of need e war of choice, sendo a primeira relacionada à guerra contra tal grupo terrorista, e a segunda relacionada ao Iraque, que por tal condição, passaria por um cronograma de retirada das tropas norte-americanas (NSS, 2010; PECEQUILO, 2011).

Paralelamente à segurança, Washington manteria sua atuação na dimensão moral, considerando que o poder dos EUA emana de seu exemplo. Em outros termos, não basta defender a democracia, os direitos humanos, a liberdade individual, a prosperidade socioeconômica, e, em contrapartida, utilizar da tortura, da restrição de privacidade a seus cidadãos e do protecionismo na economia. Para tal esfera, a administração Obama buscaria fortalecer laços com potências europeias, se aproximar das potências emergentes, destacadamente, Rússia, China, Índia, Brasil, Indonésia e África do Sul, e ampliar sua atuação em iniciativas de cunho multilateral, como o G20, o FMI e o Banco Mundial (NSS, 2010). Além de 
refletir contraposição ao unilateralismo, a importância dada a tais atores, simbolizavam o aceite de um mundo que tende à multipolaridade.

Diante deste processo de transformação da política externa norte-americana, o continente africano passou a ser visto como relevante em um cenário internacional cada vez mais interconectado. Inicialmente, tal percepção foi defendida em discurso de Obama realizado no Parlamento de Gana em 2009, quando indicado que qualquer êxito ou fracasso ocorrido na África poderia impactar nos Estados Unidos, bem como o interesse norte-americano em priorizar parcerias no continente e valorizar temas como democracia, desenvolvimento econômico, combate à corrupção, auxílio na segurança alimentar e no apoio a cooperação técnica. Três anos após Accra, outro documento que refletia o interesse de Washington junto à África foi o U.S. Strategy Toward Sub-Saharan Africa, que, dentre diversas características, apresentava objetivos nas esferas políticas (fortalecimento das instituições democráticas), econômicas (comércio, desenvolvimento e investimento) e securitárias (atuação em prol da paz e segurança).

Embora o interesse em fortalecer laços com países democráticos se manteve presente, em verdade ao longo da administração Obama o que se viu foi o engajamento limitado às dimensões da economia e, destacadamente, da segurança. Referente à dimensão econômica, o desejo em aumentar investimentos no continente, o empenho na abertura dos mercados africanos ao produtos norte-americanos e a ampliação da AGOA, que em 2015 foi estendida para mais dez anos, foram objetivos convergentes com dois fatores que, no geral, se enquadram na ideia de mundo cada vez mais interconectado. Neste caso, o primeiro fator encontra-se relacionado à própria fala do líder democrata em Gana, qual seja, que a África vinha se transformando na região que, economicamente, mais crescia no mundo e, por tais condições, poderia representar oportunidades às empresas norte-americanas (OBAMA, 2009).

De fato, se ao longo do governo Bush as transformações na África foram representadas pela criação da Nova Parceria Econômica para o Desenvolvimento da África (NEPAD, na sigla em inglês) e transição da Organização da Unidade Africana (OUA) para União Africana (UA), ao longo dos mandatos de Obama, o continente africano manteve-se aprofundando os processos de integração regional, símbolos desta nova fase de Renascimento Africano. Exemplos disso podem ser encontrados no Programa de Infraestrutura para o Desenvolvimento da África (PIDA), lançado em 2010 na cidade de Kampala, cujo principal objetivo é romper com gargalos energético, hídrico, tecnológico e de transporte que dificultam o avanço do comércio interafricano, e, principalmente, na Agenda 2063 - A África que queremos, iniciativa criada em 2015 pela UA e marcada por 15 aspirações desejadas para transformar o continente africano mais integrado, próspero e pacífico.

Já o segundo fator, e tão importante quanto o anterior, converge com a maior atuação das potências emergentes no continente africano e, neste caso, destacadamente a China, protagonista no financiamento da PIDA e, desde 2012, principal parceiro comercial do continente. Embora havendo aumento no investimento externo direto, uma vez que se em 2009 em torno de US\$ 44 bilhões foram investidos na África, em 2016 as cifras chegaram a US\$ 50 bilhões, com o ápice em 2014, com US\$ 69 bilhões, é fato que no âmbito comercial o que se viu foi o declínio. Em números, se no primeiro ano da administração Obama as exportações e importações para a África totalizaram US\$ 24, 5 milhões e US\$ 62, 4 milhões, respectivamente, em 2016, o que se viu foi a redução destas, com as exportações em US\$22,27 milhões, e importações em US\$ 26,4 milhões (STATISTA, 2021; UNITED STATES CENSUS BUREAU, 2020).

O desfavorecimento na dimensão econômica foi contrastado com a atuação no âmbito da segurança, visto que junto à valorização de temas englobados no conceito ampliado de segurança, destacadamente, a prevenção de conflitos e atrocidades em massa, meio ambiente, segurança alimentar, e no combate a doenças infectocontagiosas, como HIV/AIDS e malária, a administração Obama manteve as iniciativas desenvolvidas durante o governo Bush, bem como no repasse de recursos para países considerados estratégicos. Neste caso, vale ressaltar a maior valorização de países como Egito, que entre 2009 e 2010 havia recebido em torno de US\$1,3 bilhões em assistência militar, e o Djibuti e a Etiópia, países que 
também entre 2009 e 2010 receberam, juntos, aproximadamente a metade dos US\$12,55 milhões solicitados pelo FMF ao Departamento de Defesa (TIEKU, 2018).

Junto aos países anteriormente citados, vale ressaltar o FMF que entre 2010 e 2011 repassou em torno de US\$38 milhões distribuídos para diversos países, destacadamente, Libéria (US\$ 9 milhões), Marrocos (US\$ 9 milhões), Nigéria (US\$ 4 milhões), Tunísia (US\$ 4,9 milhões), Djibuti (US\$2,5 milhões), Etiópia (US\$ 2 milhões), República Democrática do Congo (US\$ 1,5 milhões), Quênia (US\$ 1 milhão). Além do FMF, outra iniciativa que também se destacou foi o IMET, que dos US\$ 21 milhões utilizados para treinamento e qualificação de militares africanos, Tunísia (US\$ 2,3 milhões), Marrocos (US\$1,9 milhões), Quênia, Nigéria e Senegal, todos com US\$ 1 milhão, foram os países mais beneficiados (TIEKU, 2018).

Paralelamente ao repasse de recursos, outra iniciativa adotada durante a administração Obama foi o apoio a intervenção militar voltada a mudança de regime. No caso africano, o principal exemplo refere-se à Líbia, país então sob a administração de Gaddafi (1969-2012). Embora desde o período da Guerra Fria as relações entre Líbia e EUA foram marcadas por atritos, motivados, por exemplo, pelas incursões militares norte-americanas refletidas na derrubada de aeronaves (em 1979 e 1989), e bombardeios às cidades de Tripoli e Bengazi (1991), e por acusações de que o governo líbio cooperava com grupos terroristas, em verdade, a partir da administração Bush a relação entre as partes vinha sendo marcada pela aproximação. Reflexo disso pode ser encontrado na entrada de investimentos externos diretos e no fim das sanções políticas e econômicas impostas a Tripoli (VANDEWALLE, 2012). Entretanto, com a Primavera Árabe o que se viu foi o retorno das desavenças entre as partes.

Podendo ser entendida como o conjunto de revoltas de caráter popular que passaram a acontecer em alguns países do Oriente Médio e Norte da África, fruto de anseios relacionados ao desemprego, à falta de liberdade política e o combate a corrupção (JOFFÉ, 2011), a Primavera Árabe, no caso líbio, foi caracterizada pela intervenção militar arquitetada no Conselho de Segurança pelos Estados Unidos, França e Inglaterra via instrumentalização do Responsability to Protect (R2P, na sigla em inglês). Por um lado, o respaldo conquistado com o R2P, levou à aprovação das resoluções 1970 (embargava a venda de armas) e 1973 (criava uma zona de exclusão área) (SECURITY COUNCIL, 2011a; 2011b), à intervenção da OTAN e, consequentemente, ao término da administração Gaddafi. Por outro lado, refletiu uma das principais características da política externa norte-americana, no caso, priorizar seus parceiros europeus, que possuíam interesse na intervenção.

\section{Economia, Segurança e o lugar da África na administração Trump (2017-2021)}

A dificuldade da administração Obama em romper com a polarização na sociedade norte-americana, caminhou lado a lado à ascensão de Donald Trump, candidato que venceria as eleições para presidente de 2016. Caracterizado por discursos e atos de caráter xenófobo, nacionalista, misógino, dentre outros pontos defendidos pelo radicalismo conservador, Trump direcionou sua administração no rompimento com as iniciativas adotadas anteriormente (PECEQUILO, 2017). No âmbito externo, o descrédito dado ao multilateralismo, ao fortalecimento de laços com parceiros tradicionais, bem como a difusão da economia de mercado, dos direitos humanos, da democracia e do respeito ao meio ambiente, não apenas foi marcante em sua política externa, como também simbolizaram a ruptura com a principal iniciativa norte-americana no pós-2a Guerra, qual seja, a OIL (PATRICK, 2017).

Conforme indicado anteriormente, a busca em adequar ou manter a OIL foi encontrada nas administrações Bush e Obama, respectivamente. Entretanto, quando analisada a administração Trump, o que se viu foi a não criação de uma grande estratégia, mas sim, o enveredamento por escolhas de cunho nacionalista e focadas em ganhos unilaterais, em detrimento das conquistas coletivas. Em certa medida, essa tendência já era vista no período eleitoral, com o slogan Make American Great Again e evidenciada com a expressão America First e com o lançamento da NSS de 2017, documento que apresentava a percepção norte-americana sobre o sistema internacional e como Washington deveria atuar (NSS, 2017). 
Referente a percepção, é possível indicar que o sistema internacional era marcado por ameaças, desafios e injustiças aos EUA. Ameaças, visto que o mundo era compreendido como espaço marcado por regimes desonestos e desenvolvedores de armas nucleares, pelo terrorismo islâmico no Oriente Médio, dentre outras mazelas que representavam perigo aos norte-americanos. Desafios, uma vez que os EUA estavam diante da ascensão de potências rivais que divergem de seus interesses ou da ascensão de cartéis de drogas resultantes de falhas na aplicabilidade de leis migratórias e de fronteiras consideradas porosas. Injustiça, pois Washington vem sendo impactado por práticas comerciais consideradas desleais e por parcerias e alianças que não auxiliam na estabilidade do sistema internacional (NSS, 2017).

Diante destes desafios, ameaças e injustiças, a administração Trump se pautaria em certas escolhas para cada dimensão. No combate às ameaças, a luta contra o terrorismo, contra o avanço de pandemias e a disseminação de armas de destruição em massa, a atuação em prol da redução do tráfico de drogas e de pessoas, a modernização e reaparelhamento das forças armadas e da base industrial de defesa, e a segurança cibernética dos norte-americanos, eram vistos como fundamentais. Concernente aos desafios, o caminho passava a estar atrelado à segurança nas fronteiras com os países lindeiros, bem como da economia norte-americana. Neste caso, além de políticas voltadas ao âmbito interno, como diminuição da carga tributária, incentivo às empresas investirem no país e melhoria na infraestrutura, para o âmbito internacional, os EUA deveriam forjar novos ou revisar os acordos econômicos já existentes, priorizar as exportações, dentre outras iniciativas compreendidas como necessárias e fundamentais para a revitalização da economia norteamericana (NSS, 2017).

Somadas às iniciativas direcionadas à economia, outra que ganhou destaque e corresponde à dimensão da injustiça diz respeito à crítica a países que, na concepção do governo republicano, não ajudaram a expandir a economia liberal, mas sim, apenas se beneficiaram de sua existência. Neste caso, uma das principais ferramentas para romper com tais injustiças encontra-se na diplomacia, que deveria ser mais agressiva na efetivação dos interesses norte-americanos, na contenção do avanço da China e da Rússia, que passaram a expandir suas relações econômicas em regiões e países onde os Estados Unidos eram influentes, e na atuação em organizações internacionais como o Fundo Monetário Internacional (FMI), a Organização Mundial do Comércio (OMC), dentre outras destacadas como relevantes (NSS, 2017).

Evidentemente que muitos dos pontos anteriormente indicados não foram alcançados, destacadamente o combate a pandemia, visto que os Estados Unidos assumiram o posto de país com o maior número de infectados e de óbitos relacionados a pandemia da Covid-19 (THE WHITE HOUSE, 2021). Além disso, os quatro anos em que esteve à frente da presidência foram marcados por constantes mudanças em cargos que, no geral, representou certa instabilidade interna no governo e impactou na política externa. Porém, muito das escolhas e das percepções apresentadas na NSS de 2017 marcaram a administração republicana, expondo sua contrariedade a OIL. Exemplos disso podem ser vistos na saída do Acordo Transpacífico, do Acordo de Paris sobre o Clima, do Conselho de Direitos Humanos das Nações Unidas, da Organização das Nações Unidas para a Educação, Ciência e Cultura, e na substituição do NAFTA pela Acordo Estados Unidos-México-Canadá (USMCA, na sigla em inglês) (AYERBE, 2019; GONÇALVES; TEIXEIRA, 2019).

Além de atender seu eleitorado, avesso ao multilateralismo, ao livre comércio, a imigração e ao intervencionismo por questões consideradas humanitárias, o isolacionismo norte-americano era também uma resposta à dimensão da injustiça, visto que concretizava o anseio de Trump em retirar os Estados Unidos de acordos e instituições consideradas desfavoráveis aos interesses de Washington. Inclusive, outros exemplos que podem ser citados referem-se à visão de que atuar na Síria, no Afeganistão, no processo de alargamento da OTAN e na pressão sobre a Coréia do Norte era desfavorável aos interesses americanos (GONÇALVES; TEIXEIRA, 2019). Logo, se Trump buscou negociar com o governo norte-coreano e com o Talibã, não necessariamente objetivou a paz, mas, fundamentalmente, considerou que as negociações diminuiriam gastos compreendidos como desnecessários por Washington. 
Ainda que a transformação do NAFTA para USMCA reflita a percepção de que Washington era o parceiro mais prejudicado, vale ressaltar que esta reformulação fazia parte do conjunto de críticas com relação ao México, considerado como ineficaz no combate a entrada de imigrantes irregulares nos EUA. Desta discordância, e juntamente a maior militarização da fronteira entre tais países, a principal iniciativa de Trump dizia respeito a construção do muro entre Estados Unidos e México, que desde a disputa eleitoral era destacado pelo Republicano e se manteve presente em sua gestão, embora não sendo plenamente consolidado (PECEQUILO; FRANZONI, 2019). Ainda no cenário latino-americano, vale destacar o aumento das pressões e sanções a Venezuela, Nicarágua e Cuba, país cujo acordo de aproximação criado durante a administração Obama foi cancelado por iniciativa de Trump (AYERBE, 2019).

A tendência ao embate também foi encontrada na Europa, Ásia e Oriente Médio, isto é, em espaços considerados prioritários na política externa dos EUA. Referente aos continentes, o distanciamento de parceiros como França e Alemanha, caminhou lado a lado ao aumento das pressões sobre a China, país visto como favorecido em instituições como a OMC e a Organização Mundial da Saúde (OMS), e no comercio mundial. Desta percepção, a resposta foi a saída da OMS, e o aumento na taxação dos produtos chineses que entravam no mercado norte-americano.

No Oriente Médio, a interação combativa foi encontrada na ampliação das pressões ao Irã, refletida na retirada dos EUA do Plano de Ação Conjunta Global (JCPOA, na sigla em inglês), e, destacadamente, na priorização dos interesses israelenses se comparado aos palestinos. Símbolos desta escolha podem ser encontrados na transferência da embaixada americana para Jerusalém, no fechamento da missão pertencente a Organização para a Libertação da Palestina (OLP) sediada em Washington, no encerramento do financiamento a Agência das Nações Unidas de Assistência aos Refugiados Palestinos no Oriente Próximo (UNRWA, na sigla em inglês), dentre outras iniciativas que levavam ao isolamento da Palestina (COPPOLANI, 2020).

Diante destas transformações, manteve-se à atuação na economia e na segurança, porém, seja pela diminuição ou concentração em algumas iniciativas, seja motivado por divergências relacionadas a determinados temas, o que se viu foi o retorno ao desengajamento. Na economia, o interesse pelo Golfo da Guiné convergiu com o desejo em diminuir o assistencialismo junto aos países africanos, e, destacadamente, com a criação da Trump Administration's Prosper Africa Initiative. Exposta inicialmente por John Bolton, em 2018, porém lançada em 2019 na Cúpula EUA-África em Moçambique, a Iniciativa pode ser representada por duas características. A primeira pelo fato de envolver 15 órgãos governamentais, como a Agência dos Estados Unidos para o Desenvolvimento Internacional (USAID, na sigla em inglês), o U.S. Internacional Development Finance Corporation (DFC), o U.S. African Development Foundation (USADF), dentre outros (COOK; WILLIAMS, 2020).

Já a segunda característica refere-se aos objetivos, no caso, as relações econômicas entre as partes, bem como se contrapor a presença da China no continente. O desejo em romper com o avanço chinês já havia sido destacado na NSS de 2017 e, com a Trump Administration’s Prosper Africa Initiative, era exposto que os países africanos seriam englobados nesta tendência à contenção de Pequim. Entretanto, esta estratégia não alcançou os resultados esperados, visto que a China manteve-se fortalecendo suas parcerias no continente, enquanto Washington em 2019, viu o continente contabilizar apenas $1,4 \%$ do total comercializado pelos EUA (COOK; WILLIAMS, 2020).

Inclusive, houve o declínio do IED direcionado a África, visto que se em 2016 em torno de US\$ 50 bilhões foram investidos, em 2019, a cifra declinou para em torno de US\$ 43,2 bilhões, valor próximo ao montante investido em 2009 , quando os Estados Unidos se encontravam na conjuntura da crise financeira de 2008. Neste caso, a discrepância nos números relacionados aos IEDs pode ser encontrada na comparativa com outras regiões, como América Central e Sul, que entre 2009 e 2019 variou entre US\$ 217 bilhões e US\$ 256 bilhões, e a Ásia Pacífico, que neste mesmo período passou de US\$ 503 bilhões para US\$ 955 bilhões, valores que reforçam o status da África de região que menos recebe investimentos advindos dos EUA (STATISTA, 2021). Em termos gráficos: 
Imagem 1- Investimento Externo Direto dos Estados Unidos

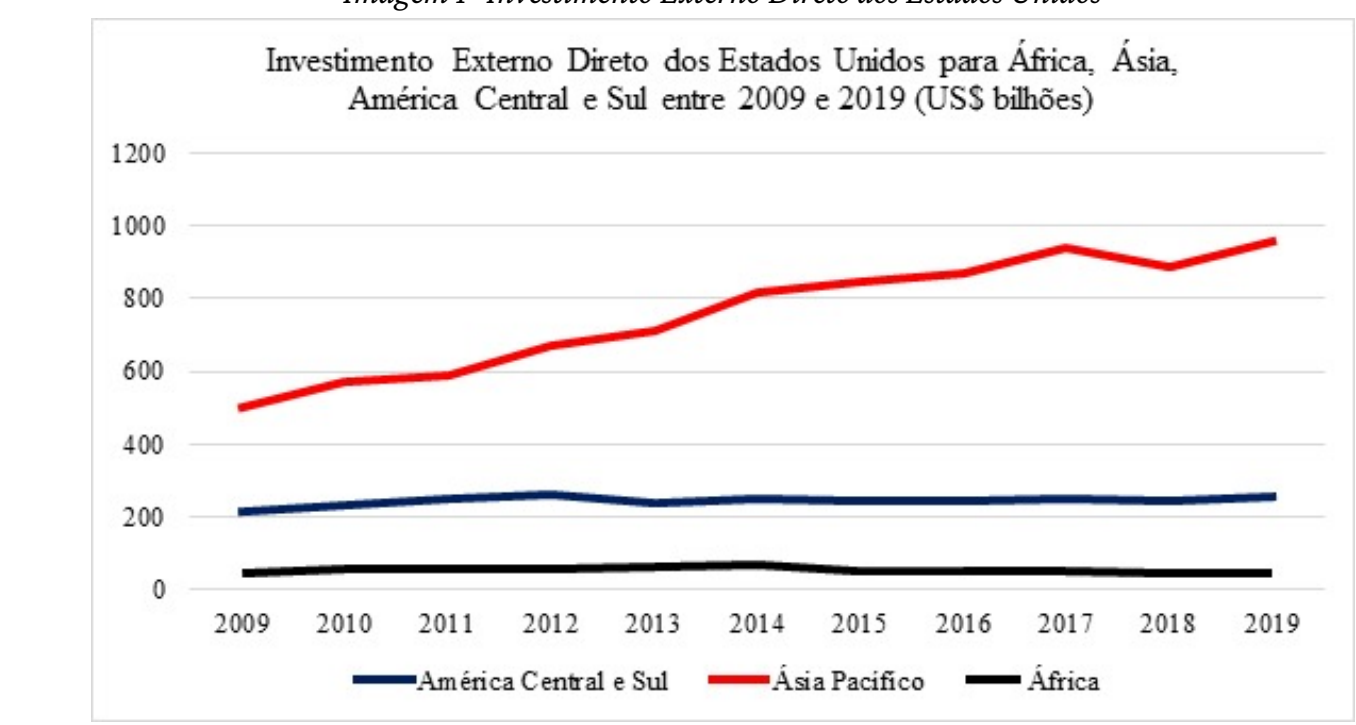

Fonte: Elaborado pelo autor com dados de Statista (2021)

Referente ao âmbito da segurança, Washington priorizou a região composta por Magreb, África Oriental e Chifre da África, espaço compreendido conexo ao Oriente Médio, logo, propenso ao avanço do terrorismo, e a aproximação junto a Nigéria, África do Sul, Argélia, Etiópia, Senegal, enfim, países considerados importantes para a estabilidade do continente (SCHRAEDER, 2018). Em certa medida, a priorização dos países e regiões indicadas buscava englobar a África em dinâmicas de estabilidade e paz voltadas ao sistema internacional e no combate ao terrorismo, e não se direcionava a atender as demandas africanas. Reflexo disso pode ser encontrado no predomínio dos investimentos na criação ou manutenção de iniciativas voltadas ao terrorismo, como a Trans-Saharan Counter-Terrorism Initiative (TSCTI), o CJTF-HOA, EACTI, a IMET e, destacadamente o AFRICOM, que em 2018 foi marcado pela presença de 6.000 soldados norteamericanos, e iniciativas como o acordo com o Níger e o uso de bases no Djibouti, Itália e Tunísia para realização de ataques contra grupos terroristas, como o Estado Islâmico e a Al-Qaeda em solo líbio e somali (SCHRAEDER, 2018).

Em contrapartida, outras demandas africanas foram colocadas em segundo plano, inclusive, com a diminuição de recursos direcionados a iniciativas de caráter socioeconômico, e o desinteresse em atuar na pacificação da Líbia, compreendida como uma questão europeia. Junto ao caso líbio, as críticas africanas à administração Trump convergiram com o tratamento dado a questão imigratória. Neste caso, eram respostas a políticas como o Ato Executivo no 13.769 de 2017 que, mesmo contestado pela suprema corte, trazia como objetivo limitar a entrada de africanos advindos da Líbia, Somália e do Sudão, bem como reduzir para 50 mil o número de refugiados que poderiam ser admitidos nos EUA. Além disso, a contestação africana relacionava-se a Proclamação Presidencial 9.645, também de 2017, que restringia viagens para países como Chade, Líbia e Somália, e o encerramento do acordo firmado durante a administração Clinton que garantia aos liberianos a possibilidade de trabalhar temporariamente nos EUA (SCHRAEDER, 2018).

\section{Considerações finais}

Ao longo do artigo buscou-se analisar o lugar da África na política dos Estados Unidos entre 2001 e 2020. Durante as administrações Bush e Obama, ainda que diametralmente opostas em suas sugestões de atuação no cenário internacional, em verdade foi possível destacar a tendência de ambos em ampliar as interações com o continente africano. Referente ao governo republicano, vale destacar que além da manutenção da AGOA, da criação do MCC, do Fundo Global de combate à tuberculose, malária e ao HIV/AIDS, do PEPFAR, dentre outras pertencentes aos âmbitos econômico e sanitário, o que se viu foi o desenvolvimento de diversas iniciativas na esfera da segurança, como os programas FMS e FMF, o EACTI, ATA, Safe Skies, PSI, CJTF-HOA, IMET e, destacadamente, o AFRICOM. Conforme exposto no artigo, a 
preponderância da segurança, não necessariamente significava atenção de Washington em atender demandas africanas, mas, fundamentalmente, em enquadrar o continente aos interesses de Washington no âmbito sistêmico, especificamente a GcT.

Essa tendência de enquadramento da África, em maior ou menor intensidade, foi encontrada na administração Obama, que mesmo buscando fortalecer laços econômicos, cujo êxito não foi alcançado, também se destacou pelo predomínio no âmbito da segurança. Neste caso, somado ao envio de recursos para países considerados estratégicos para a estabilidade da África, como Egito, Djibuti e Etiópia, e na continuidade de iniciativas direcionadas a combater o terrorismo que foram criadas no bojo da Guerra contra o Terror, o que se viu também foi a adoção de política direcionada à mudança de regime. Exemplo disso foi o apoio dado à intervenção da OTAN na Líbia com o propósito de findar com a administração Gaddafi.

Se durante a administração democrata o caso líbio simbolizou o engajamento dos Estados Unidos na África, o mesmo país africano também exemplificou o desinteresse dos EUA pelo continente africano durante o governo Trump, visto que o republicano não demonstrou interesse em pacificar a Líbia, que se mantém instável até os meses iniciais de 2021 e, direta e indiretamente, afeta o continente como um todo. Junto a este descaso, o desengajamento também pôde ser visto na priorização de determinadas regiões e países considerados importantes para a estabilidade do continente, no investimento em iniciativas voltadas ao contraterrorismo desenvolvidas anteriormente e, destacadamente, na política migratória, encontrada no Ato Executivo no 13.769, e na Proclamação Presidencial 9.645, ambos de 2017 que, em essência, tinham como objetivo barrar a entrada de imigrantes e, consequentemente, dificultava o acesso aos Estados Unidos de determinados grupos africanos, como os muçulmanos. Em outros termos, o hiato existente entre o engajamento durante as administrações Bush e Obama e o desinteresse pela África no governo Trump, acabou por demonstrar a não mudança de status do continente africano na política externa norte-americana.

De modo geral, mantida a tendência dos EUA em englobar a África aos seus interesses no âmbito sistêmico, é possível encontrarmos que na recém-empossada administração, Joe Biden, o continente africano poderá ganhar destaque. Neste caso, não necessariamente pelo interesse do democrata em romper com os desafios africanos, mas, principalmente, pelo acirramento entre Washington e Pequim. Conforme apresentado neste artigo, um dos objetivos relacionados à atuação dos EUA na África dizia respeito ao caráter reativo norte-americano à presença chinesa. No caso Biden, seja pelos argumentos apresentados em artigo publicado na Foreign Affairs em 2020 intitulado de "Why America Must Lead Again: Rescuing U.S. Foreign Policy After Trump”, seja pelo discurso realizado no Departamento de Estado em 4 de fevereiro de 2021, tal disputa tende ao acirramento, fato que, consequentemente, poderá impactar nos países africanos, que possuem em Pequim o seu principal parceiro comercial.

\section{Referências}

ALMEIDA, J. M. A hegemonia americana e a ordem internacional de Clinton a G.W.Bush. JANUS: Observatório de Relações Exteriores da Universidade Autônoma de Lisboa, 2002. Disponível em: < https://repositorio.ual.pt/handle/11144/1796>. Acesso em: 20 fev. 2021.

ARRIGHI, Giovanni. O longo século XX: dinheiro, poder e as origens do nosso tempo. Rio de Janeiro; São Paulo: Contraponto; UNESP, 1996.

AYERBE, L. F. Estados Unidos e América Latina: a construção da hegemonia. São Paulo: Editora UNESP, 2002.

AYERBE, L. F. La Política de la Administración Trump para América Latina: Reinención de la Doctrina Monrore? Revista tempo de mundo. Brasília: v. 5, n.1, p. 225-240, 2019.

BANJO, A. U.S. development diplomacy in Africa: From Bill Clinton to George W. Bush. African Journal of Political Science and International Relations, [S.1.], n.4, v. 4, p. 140-149, 2010.

BIDEN, Joseph R. Why America Must Lead Again - Rescuing U.S. Foreign Policy After Trump. Foreign Affairs. Council on Foreign Relations: March/April, p.1-18,2020.

BRESSER-PEREIRA, L. C. A crise financeira de 2008. Revista de Economia Política, [S.1.], v. 29, n. 1, pp. $133-149$, 2009. 
CARDOSO, N. C. C. Segurança Regional no Chifre da África: Conflitos, Atores, Agendas e Ameaças. Porto Alegre: UFRGS, 2020.

CARVALHO, F. C. Entendendo a Recente Crise Financeira Global. Porto Alegre: IBASE, 2008. Disponível em: < http://www.ppge.ufrgs.br/akb/clipping/9.pdf >. Acesso em: 22 de dez. 2015.

COOK, N; WILLIAMS, B. R. The Trump Administration's Prosper Africa Initiative. Washington: Congressional Research Service, 2020 COPPOLANI, A. If I Forget Thee O Jerusalem. In QUESSARD, Maud; HEURTEBIZE, Frédéric; GAGNON, Frédérick. Alliances and Power Politics in the Trump Era - America In Retreat? Switzerland: Palgrave Macmillan, p. 75-99, 2020.

DERGHOUKASSIAN. K. O Estado Cortesão nas Relações Internacionais: a disputa por poder e lucro. Contexto Internacional, Rio de Janeiro, v. 24, n. 2, p. 267-328, 2002.

FROELICH, I. V. A Política Externa Americana e seus críticos. Revista Brasileira de Política Internacional. Brasília: v. 48, n. 2, p. 205 $215,2005$.

GONÇALVES, W; TEIXEIRA, T. Trump e a Inflexão da Grande Estratégia. Revista Tempo do Mundo. Brasília, v.5, n.1, 177-200, 2019.

HIRSH, Michael. Bush and the world. Foreign Affairs, New York, v. 81, n. 5, p. 18-43, Sept./Oct. 2002.

IKENBERRY, G. J. America`s imperial ambition. Foreign Affairs, New York, v. 81, n. 5, p. 44-60. 2002.

JAGUARIBE, H. O segundo mandato. Política Externa, [S.1.], v. 13, n. 4, 2005.

JOFFÉ, G. A Primavera Árabe no Norte de África origens e perspectivas de futuro. Relações Internacionais, Lisboa, v. 30, p. 85-116, 2011. JONES, V. C. WILLIAMS, B. R. U.S. Trade and Investment Relations with sub-Saharan Africa and the African Growth and Opportunity Act. Washington: Congressional Research Service, 2012.

JUDT, T. Postwar: A History of Europe since 1945. New York: The Penguin Press, 2005.

KAGAN, Robert. The benevolent empire. Foreign Policy, Washington D.C., p. 24-35, Summer 1998

KATITO, G. Continuity, little change?: US-Africa Policy under the Obama administration. OASIS: Observatorio de Análisis de los Sistemas Internacionales. Bogotá: n. 14, p. 145-157, 2010.

KLARE, M; VOLMAN, D. America, China \& Scramble for Africa's Oil. Review of African Political Economy, v. 33, nº 108, p. 297-309, 2006.

NSS. National Security Strategy For A New Century. Washington D.C.: National Security Council, 2002.

NSS. National Security Strategy For A New Century. Washington D.C.: National Security Council, 2010.

NSS. National Security Strategy For A New Century. Washington D.C.: National Security Council, 2017.

NYE, J. S. The rise and fall of American hegemony from Wilson to Trump. International Affairs: Oxford University Press, v. 95, n. 1, p. 63-80, 2019.

OBAMA, B. President Obama's Speech to Ghana's Parliament - A New Moment of Promise. Accra: 2009. Disponível em: < https://bityli.com/uM1k5 >. Acesso em 21 fev. 2021.

OBAMA, B. Renewing American Leadership. Foreign Affairs. Council on Foreign Relations: July/August, 2007.

PATRICK, S. M. Trump and World Order: The Return of Self-Help. Foreign Affairs. Council on Foreign: March/April, 2017.

PECEQUILO, C. S. A política externa dos Estados Unidos: continuidade ou mudança? Porto Alegre: UFRGS, 2011.

PECEQUILO, C. S. Os Estados Unidos de H. Bush a Donald J. Trump (1989/2017): Dinâmicas Políticas de Consenso e Polarização. Revista Esboços. Florianópolis, v. 24, n. 38, p. 339-359, 2017

PECEQUILO, C. S; FRANZONI, M. As relações bilaterais do México com os Estados Unidos: um balanço de 2000 a 2018. Revista Carta Internacional. Belo Horizonte, v. 14, n. 3, p. 110-141, 2019.

SCHMIDT, E. Foreign intervention in Africa: from Cold War to the war on terror. Cambridge: Cambridge University Press, 2013.

SCHRAEDER, P. “Making America Great Again” Against the Backdrop of na “Africa Rising”? The Trump Administration and Africa's Marginalization within U.S. Foreign Policy. Seton Hall Journal of Diplomacy and International Relations. Seton Hall University Press, p. 98-117, 2018. 
SECURITY COUNCIL. Resolution 1970. New York, 26 Feb. 2011a. Disponível em: <https://bityli.com/KEmf7>. Acesso em: 19 fev. 2021. SECURITY COUNCIL. Resolution 1973. New York, 17 Mar. 2011b. Disponível em: <https://bityli.com/x2UA0>. Acesso em: 19 fev. 2021. SHLEIFER. A. TREISMAN. D. A Normal Country: Russia After Communism. Journal of Economic Perspectives, [S.1.], v. 19, n. 1, p. 151174,2005

STATISTA, Business Data Platform. Hamburg: 2021. Disponível em: < https://www.statista.com/> Acesso em 28 mar. 2021

TEIXEIRA, C. G. P. O pensamento neoconservador em política externa nos Estados Unidos. 2007, 128f. Dissertação defendida no Programa San Tiago Dantas de Pós-Graduação em Relações Internacionais (PUC-SP, UNESP e UNICAMP). São Paulo, 2007.

THE NEW YORK TIMES, Defense Planning Guidance. New York: $1992 . \quad$ Disponível em: < http://nsarchive.gwu.edu/nukevault/ebb245/doc03_extract_nytedit.pdf >. Acesso em: 12 jan. 2021.

THE WHITE HOUSE. National Strategy for the COVID-19 Response and Pandemic Preparedness. Washington: 2021.

THE WHITE HOUSE. Remarks by President Biden on America's Place in the World. Washington: 2021.

THE WHITE HOUSE. U.S. Strategy Toward Sub-Saharan Africa, Washington: 2012.

THOMSON, S. Rwanda: from genocide to precarious peace. New Haven: Yale University Press, 2018.

TIEKU, T. K. United States-Africa Relations in the Age of Obama. New York: Cornell University Press, 2018.

UNITED STATES CENSUS BUREAU. Trade in Goods with Africa. 2020. Disponível em: < https://bityli.com/z7LNi>. Acesso em: 19 fev. 2021.

VANDEWALLE, D. A History of Modern Libya. New York: Cambridge University Press, 2012.

WIJK, R. The limits of military power. The Washington Quartely, Washington, v. 25, n. 1, p. 75-92, 2002.

ZAKARIA, Fareed. The future of american power: how America can survive the rise of the rest. Foreign Affairs, New York, v. 87, n. 3, May/Jun. 2008

Funções de colaboração exercidas

Anselmo Otavio:

Investigação; Escrita (primeira redação);

Informações fornecidas pelo autor de acordo com a Taxonomia de Funç̃ós de Colaborador (CRediT) 